\title{
Temperamental Factors in the Execution of Interrupted Editing Tasks
}

\author{
PETER T. VAN DEN BERG*, ROBERT A. ROE, FRED R. H. ZIJLSTRA \\ and IRENE KREDIET \\ Work and Organization Research Centre, Tilburg University, Tilburg, \\ The Netherlands
}

\begin{abstract}
The question investigated in this study is how the temperament traits of strength of excitation (SE), strength of inhibition (SI), and mobility (MO) affect behaviour during the execution of computer tasks and tasks interrupting them. Several hypotheses, partly derived from the regulative theory of temperament, were tested in an experiment in which the natural environment and the types of task commonly performed by secretaries were simulated. The sample consisted of 39 female secretaries (21-64 years old). It was found that individuals high on SE and MO needed less time to resume tasks after an interruption than individuals low on these temperament traits. Interruptions similar to the main task resulted in longer resumption times for low-SE individuals. MO was negatively related to the time needed to perform the main task. $A$ model describing the relationship between the frequency of switches between tasks and the speed of task performance in low-MO and high-MO individuals is presented.
\end{abstract}

\section{INTRODUCTION}

The relationships between temperament traits and the execution of tasks have been studied often (see e.g. Strelau, 1983). Generally, it has been found that temperament relates to the way a task is done but does not affect performance. However, some temperament traits also relate to performance. No studies are known to the authors that link temperament to the handling of interruptions in task execution. The aim of the present study was to determine the influence of temperament traits on the execution of computerized text editing tasks and the handling of interruptions.

*Correspondence concerning this article should be addressed to Peter T. Van den Berg, Department of Psychology, Tilburg University, P.O. Box 90153, 5000 LE Tilburg, The Netherlands. Electronic mail may be sent via Inernet to P.T.vandenBerg@kub.nl 


\section{Temperament traits}

Temperament traits are defined as the relatively stable energetic and temporal characteristics of behaviour describing the how of actions without referring to the content (Strelau, 1983, p. 171). Many of the temperament traits described in the psychological literature are derived from Pavlov's (1955) studies on stable individual differences in conditioned learning. Several other temperament concepts have been developed, e.g. by Thomas and Chess (1977). In this study we confine ourselves to the most important temperament traits studied within the Pavlovian tradition, i.e. strength of excitation (SE), strength of inhibition (SI), and mobility (MO). The neoPavlovian typologists Teplov and Nebylitsyn enlarged the number of traits. Nebylitsyn (1972) distinguished between the strength, the dynamism, the MO, and the lability of excitation, inhibition, and balance, thus discerning 12 properties. However, these new concepts did not add much to the original model.

To study temperament traits outside the laboratory, Strelau (1983) constructed the Strelau Temperament Inventory (STI) consisting of scales for SE, SI, and MO. SE refers to the ability to build up a conditioned response and is negatively related to the cortical arousal a certain stimulus elicits. The trait expresses itself in the ability of an individual to react adequately in situations of intense or long-lasting stimulation. $\mathrm{SI}$ is defined in terms of the ability of the central nervous system to maintain a state of conditioned inhibition, such as extinction or delay of reinforced behaviour. HighSI individuals are able to ignore distracting information and to refrain from undesirable behaviour. MO is the ability to react quickly to changes in the environment. Klimov (1959) showed that in a group of 35 weavers, 'mobile' individuals tried to perform their tasks more rapidly, but spent less time on orienting activity than 'slow' individuals. However, the two groups did not differ in performance. This trait has two components: speed of elicitation of reaction (liveliness) and speed of extinction of response (perseveration). SE and SI describe the energetic dimensions of temperament, and MO refers to the temporal aspect.

Strelau (1983) has formulated a regulative theory of temperament. It belongs to the category of arousal-oriented theories, along with Eysenck's (1967) P.E.N. theory and Zuckerman's (1979) theory on sensation seeking. Following Furnham and Zacherl (1986), these theories are the most promising of the personality theories. In his theory Strelau uses the concept of reactivity rather than SE. Reactivity can be considered as the reverse of SE. Individuals high on SE are low on reactivity, and vice versa. Reactivity is defined as 'a temperament feature which determines the relative stable and characteristic intensity (magnitude) of reactions for a given individual' (Strelau, 1983, p. 177). Generally speaking, there is a parabolic relationship between the intensity of stimuli (loudness of sound or brightness of light) and the intensity of the conditioned response. If stimulus intensity is very low, the intensity of the response will be low because of the low energy level elicited. However, if stimulus intensity is beyond the endurance threshold, the level of arousal is too high to react adequately. Stimuli of medium intensity cause the most intense reactions. The intensity of reactions is co-determined by the reactivity of the individual, as can be seen in the inverted U-curves in Figure 1. High reactives respond to stimuli of lower intensity (sensitivity threshold) than low reactives, but low reactives can endure stimuli of higher intensity (endurance threshold) than low reactives. 


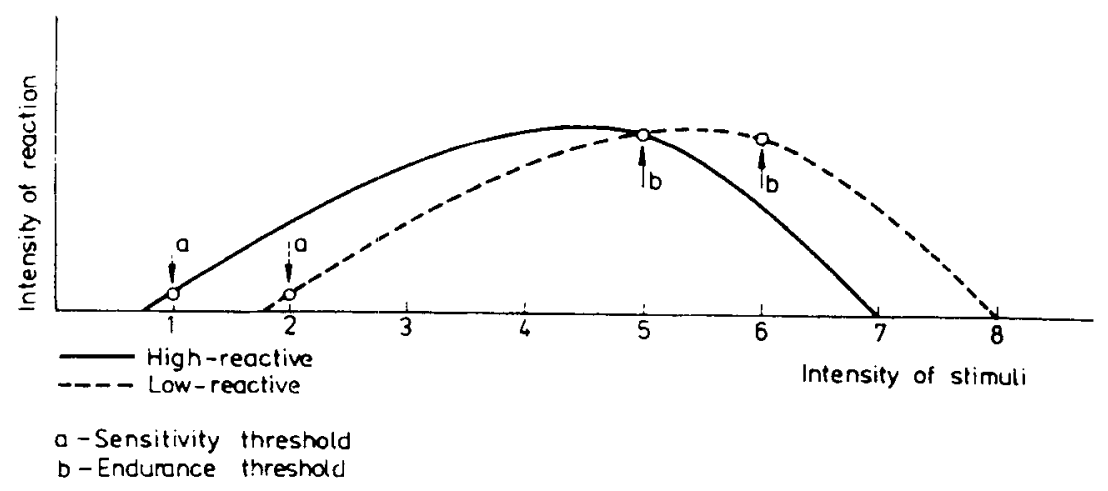

Figure 1. Model of the intensity of reactions as a function of the intensity of stimuli in highreactive and low-reactive individuals (from Strelau J. (1983) Temperament, Personality, Activity, Academic, London, p. 178. Copyright 1983 by Academic Press. Reprinted with permission).

According to Strelau (1983, p. 179), the physiological mechanisms determining reactivity are very complex and consist of interconnected systems responsible for the release of energy, such as receptor systems, the endocrine system, the neurotransmittance system, the autonomic nervous system, and the reticular formation. In order to describe the role of activity, in this context, Strelau refers to the concept of optimal level of arousal (cf. Hebb, 1955). Strelau (1983) made a distinction between activities as direct sources of stimulation, and activities as indirect sources of stimulation. As has been shown in many studies (e.g. Fiske and Maddi, 1961; Zuckerman, 1979), the individual's own activity, for example, risk taking or seeking new experiences, may be a direct source of stimulation. Following Strelau (1983), activity also serves as an indirect source of stimulation because it 'organizes' the sources of stimulation. Specifically, the theory says that there is a difference between people's action styles. High-reactive individuals tend to engage in more auxiliary actions when performing a task compared with low-reactive individuals. Such auxiliary actions, for instance, preparing, correcting, controlling, and so-called 'protective actions', may have the effect of decreasing the stimulative or arousing value of the main activities.

Empirical support for the role of activity as an indirect source of stimulation was found in several studies. For example, Kopytova (1964) found that in nonstressful conditions, operators high on reactivity, i.e. low on SE, engaged in significantly more controlling and preparing actions than operators with a low reactivity. However, in threatening situations, the orienting, control, and executive activity was inhibited in high-reactivity individuals. Mündelein and Schönpflug (1983) arranged laboratory conditions similar to the natural settings of insurance agents working with a computer. Reactivity as measured with STI-SE was related to the frequency of auxiliary activities (making notes, preparing pens, and closing the window). 
The STI was constructed to measure three Pavlovian constructs. On the basis of the regulative theory of temperament Strelau (1993) developed a new questionnaire: the Formal Characteristics of Behaviour-Temperament Inventory (FCB-TI).

\section{Interruptions in the execution of computer tasks}

Computers are omnipresent in organizations, being common tools at work (see e.g. Roe et al., 1993). In a group of subjects performing mental information work, defined as work with information and information objects in which mental activities predominate, 88 per cent used a computer at work. In the remaining group not performing mental information work, only 48 per cent used a computer at work. The relevance of interruptions during the execution of computer tasks was demonstrated by Johansson and Aronsson (1984) who found that in computerized administrative work, interruptions by other types of activity, such as answering questions and picking up the phone, are a main source of stress reactions.

The first who studied the effects of interruptions during task performance was Zeigarnik (1927). The tasks used by Zeigarnik ranged from simple manual ones, such as stringing beads, to more complex tasks, such as solving problems. She showed that, when a task was interrupted by another activity, the task was better recalled than when a subject was not interrupted. This Zeigarnik effect has been explained by the tension system discharged by the completing of a task. Recently, Gillie and Broadbent (1989) have shed new light on this matter. The main task consisted of a computer-based adventure game in which subjects had to discover the right commands to achieve certain goals. It was found that similarity of the interrupting task to the main task and the complexity of the interrupting task determined whether an interruption negatively affected the speed of task execution. The memory load at the time of interruption and the length of the interruption interval were not conceived of as important factors. The effect of the opportunity to rehearse the main task before processing the interrupting task was unclear. In another study (Field, 1987) it was found that interruptions of computer tasks increased the number of errors made in the post-interruption period. An interruption is defined as an externally generated, temporary cessation in the current flow of behaviour, typically meant for the subject to execute activities that belong to a secondary set of actions. The activities of the primary task are resumed after a certain lapse of time. A typical example of an interruption is answering the telephone.

The allocation model developed by Kahneman (1973) can explain why some interruptions disrupt task performance. Kahneman suggests that, in the face of the higher demands posed by the interruptions, the level of arousal becomes higher and thereby increases the available capacity of the individual. After some time, a high level of arousal may disrupt the allocation of resources. Interruptions place greater demands on the individual because the main activity has to be stored in memory, while paying attention to the interrupting task. In addition, interruptions of the ongoing activity require new allocations of mental resources. Because task interruptions can be conceived of as intense stimuli, SE may moderate the effects of interruptions.

Another view is given by Cellier and Eyrolle (1992) who showed that, in switching from one task to another, two processes are required to maintain the level of performance: the inhibition of the interrupted activity and the activation of the 
new activity. A high level of SI may facilitate the first process. MO may be involved in the speed of both processes. Because interruptions require a transition to another activity and back again MO may also be a moderator of the effects of interruptions. That MO is related to flexibility in the execution of tasks has been shown by Strelau (1977) who tested a group of 112 pupils, aged 16-18, and related their scores on the MO scale of the STI with scores on tests measuring semantic and figural fluency and flexibility. The tests derived from the model of Guilford (1967) required the subjects to name new uses for three objects (semantic), and to interpret three abstract drawings (figural) within three minutes. The number of constructs (fluency) and the number of classes of constructs (flexibility) were scored. The correlation between MO and the overall score on the tests was $r=0.32$, $p<0.01$. Koscielak (1979) also found that, in a group of shipyard workers, MO was related to flexibility of thinking, as measured by tests, and to creativity in their work.

\section{Aims of the present study}

This study investigated the influence of temperament traits on the execution of tasks, especially on the execution of computer-based tasks that are interrupted by external sources. Earlier research on the influence of temperament on task execution has included experimental laboratory studies, observational studies, and survey studies with questionnaires (see Strelau, 1983). Each of these types of study has its limitations. Laboratory studies often cannot be generalized to natural settings; observational and cross-sectional survey studies typically lack the experimental control, and therefore they cannot assess causal relationships. The present study combines the virtues of the three types of study. An experiment was conducted with secretaries performing the types of task they normally carry out in their own jobs. The subjects performed these tasks under controlled conditions in a simulated work setting showing great resemblance to their natural work setting. The experimental sessions were videotaped for observational analysis. Several questionnaires were also administered.

The general hypothesis was that individual differences in the execution of administrative computer tasks and in their reactions to interruptions during these tasks are related to temperament traits. On the basis of earlier research findings, seven hypotheses were formulated. First, we hypothesized that individuals low on SE engage in more auxiliary actions than individuals high on SE. This hypothesis follows directly from the regulation theory of temperament which states that highreactive individuals (low on SE) try to decrease the level of stimulation by engaging in preparatory actions, asking for help, controlling, and so on.

Second, we expected that high-SE individuals need less time to resume the main task after an interruption. Because Field (1987) showed that interruptions have a detrimental effect on performance in the post-interruption period, we assumed that interruptions during task performance generally increase arousal beyond the optimal level, and, following the regulative theory of temperament, we expected individuals high on SE to cope better with strongly arousing stimuli than individuals low on this trait.

Third, it was hypothesized that for individuals high on SE the similarity between the interrupting task and the main task has a stronger effect on the time needed to 
resume the main task than for individuals low on SE. This hypothesis was derived from the regulative theory of temperament which states that strong stimuli are more disruptive for high reactives than for low reactives. That interruptions by tasks similar to the interrupted tasks are strong stimuli has been shown in the study of Gillie and Broadbent (1989) in which these tasks lowered the speed of performance. This is in accordance with Strelau's (1983) theory that high-reactive individuals (low on SE) prefer heterogeneous actions over homogeneous actions because they want to give the overburdened nervous system a chance to recover.

Fourth, we hypothesized that for high-SE individuals compared with low scorers on SE mood is more positively affected by the execution of a stimulating task. This hypothesis was derived from Eysenck's (1967) theory on extraversion. In the same way as in Figure 1, Eysenck theorized that extraverts have a higher optimal level of stimulation than introverts. However, his dependent variable, indicated on the vertical axis, was hedonic tone, i.e. feeling good or bad. Because many studies have shown that extraversion is highly correlated with SE (see Strelau, 1983), hedonic tone may also be used as a dependent variable in connection with the regulative theory of temperament. Therefore, individuals high on SE are expected to experience a task with a high level of stimulation more positively than individuals low on this trait.

The fifth hypothesis was that individuals high on MO resume an interrupted task more quickly than individuals low on MO. This hypothesis follows from the large number of studies (Strelau, 1983) showing that MO is related to the speed of reacting to new stimuli. In fact, this relationship is implied by the fact that MO is defined as the ability to react quickly to changes in the environment. Therefore, the hypothesis refers to the construct validity of the measure for MO.

In the sixth hypothesis, we stated that individuals high on MO can perform tasks requiring rapid switches of attention to successive parts of the task more quickly and with less effort than low scorers on MO. This expectation was based on the relationship between $\mathrm{MO}$ and flexibility mentioned earlier.

The seventh hypothesis is that SI is related to the number of actions during the execution of a task consisting of many subtasks. This hypothesis was derived from the notion that high levels of SI facilitate the inhibition of the present action. Individuals high on SI can easily abandon an action when it turns out to be unsuccessful, or when a new action has to be undertaken.

\section{METHOD}

\section{Subjects}

Thirty-nine women participated in the experiment. Their mean age was 39 years ranging from 21 to 64 . All participants were professional secretaries and had a paid position at Tilburg University. All of them were familiar with the WordPerfect 5.1 word processing programme, which they used in their daily work. They were also familiar with the type of task: editing a document following various instructions. They participated voluntarily, but they received a reward afterwards. The participants belong to an occupational category that has been found to experience some of the negative impacts of interruptions (Krediet, 1994). 


\section{Measures}

The Pavlov Temperament Schaal (PTS; Van Heck, De Raad and Vingerhoets, 1993) was used for the measurement of SE, SI, and MO. This questionnaire is a Dutch translation of the STI-R (Strelau, Angleitner, Bantelmann and Ruch, 1990) which measures SE, SI, and MO. Each of these scales consists of 20 items with four response categories ranging from agree completely to disagree completely. In a sample of 338 subjects, the means, standard deviations, and Cronbach alphas of the respective scales were $49,8.3$, and 0.88 (SE), 49.9, 6.5, and 0.78 (SI), and 56.5, 8.7, and 0.91 (MO) (Van Heck et al., 1993).

The items of the SE scale relate to the following seven SE components: (i) continuing a planned action in spite of threatening situations; (ii) being prone to undertake actions in highly stimulating situations; (iii) preferring to carry out risky activities; (iv) not being emotionally disturbed under a social and physical load; (v) performing efficiently in highly stimulating situations; (vi) being able to withstand fatigue; and (vii) reacting adequately under strong emotional tension.

The items of the SI scale measure five components: (i) refraining from socially undesirable behaviour; (ii) easily delaying task performance; (iii) being able to interrupt actions if necessary, (iv) being able to delay reactions to acting stimuli; and (v) being able to hold back expression of emotions when required.

The items on the MO scale also describe five facets: (i) reacting adequately to unexpected changes; (ii) adapting quickly to new surroundings; (iii) moving easily from one activity to another; (iv) changing mood easily; and (v) preferring activities to be performed simultaneously.

The action styles of goal-directedness and planfulness were measured with the Action Style Questionnaire (ASQ; Frese, Stewart and Hannover, 1987). The general form of the ASQ used in this study begins with the phrase 'In general, when I do things ... . Next, 18 bipolar items with two possible actions followed (e.g. '. . I took all of my goals very seriously' [versus] '. . . my goals might have been important, but I sometimes lost sight of them'). The subjects had to indicate the action that is closest to their own action on a five-point scale. The response categories are very true of me and somewhat true of $m e$ in both directions, and I am in the middle between them. In a sample of 100 German psychology students, the Cronbach alpha for the seven-item Goal Orientation scale was 0.70 , and the Cronbach alpha for the Planfulness scale consisting of eight items was 0.76 .

To assess the general mood of the subjects and their mood after the experimental sessions, the Positive and Negative Affect Schedule (PANAS; Watson, Clark and Tellegen, 1988) was administered. The PANAS consists of ten adjectives describing positive affect (PA; e.g. 'enthusiastic', 'interested', 'determined'), and ten items describing negative affect (NA; e.g. 'scared', 'afraid', 'upset'). The subjects were asked to rate how they felt 'right now, that is, at the present moment' (state form), or 'in general, that is, on average' (trait form). The items have five-point scales ranging from very slightly or not at all to very much. Watson et al. (1988) reported internal consistency coefficients (Cronbach alpha) for the PA and NA state scales of 0.89 and $0.85(N=660)$, and for the PA and NA trait scales of 0.88 and $0.87(N=663)$.

The Rating Scale Mental Effort (RSME), developed by Zijlstra (1993), was used for the measurement of mental effort. This rating scale has verbally labelled anchor 
points indicating particular levels of effort investment. The nine labels range from required great effort to required no effort. The lowest scale value is 0 , and the highest value is 150 . The average correlation between the ratings of effort exerted in four similar computer-based memory tasks was $r=0.76$ (Zijlstra, 1993).

The performance measures used were the total time spent on the main task, the time from the beginning to the end of an interruption, and the time needed to resume the main task after completing the interrupting task. The numbers of seconds were scored. The errors were defined by the number of instructions omitted and the number of incorrectly performed instructions left after the execution of the main task.

The behaviour of the subjects during the execution of the main task was classified into three categories of actions: (i) main actions directly related to the main tasks; (ii) auxiliary actions supportive of the main actions (e.g. using the help function, making notes); (iii) non-relevant behaviour that has nothing to do with the main task (e.g. looking around). The number of actions per minute were calculated.

\section{Apparatus}

The experiments took place in a simulated office environment. The simulated office consisted of an approximately $45 \mathrm{~m}^{2}$ room with three workplaces, each consisting of a chair and a desk with regular office supplies, including a PC, a telephone, and a mail basket. Some bookcases and plants were present as well. The furnishing of the office, i.e. decoration, furniture, and equipment can be considered to be in compliance with Dutch office standards and with relevant ergonomic criteria. In addition to what can be found in a normal office, there were some recording and measurement devices, such as a one-way observation screen, a number of video cameras mounted on the ceiling, a keystroke registration device inside the $\mathrm{PC}$, and a portable heart pulse recording device. These facilities provided the opportunity to record all on-going activities of the subjects.

The experimenters could observe the subjects, and communicate with them by telephone from an adjacent control room. The experimenters could also observe the subjects via the video monitors placed in the control room. The video recordings included sound recordings. A specially developed system, called CAMERA (distributed by iec ProGAMMA, Groningen) was used to add a time code to a track on the video-tape. This system allowed to define various behavioral categories (maximally 32) and to allocate these categories to a corresponding number of keys on a keypad. Consequently, the observer(s) only had to press the relevant key when a particular behavioural category was observed.

\section{Design and procedure}

The experiment consisted of three sessions a day on two consecutive days. During each session, the subjects had to perform a text editing task of moderate complexity, as occurring in the daily work of secretaries. A printed version of a text containing handwritten instructions for editing was presented along with a diskette containing a text file. The instructions had to be executed by means of the WordPerfect 5.1 programme. The instructions called for typing and formatting the document, changing fonts, replacing parts of the text, correcting, etc. A set of similar tasks was 
available to be used in each of the sessions. Before and after the experimental sessions, a diagnostic interval was scheduled during which several measures were taken. There was no time limit, and the subjects were free to choose their own method of working. The tasks were chosen so that their (undisturbed) execution would take about $1 \mathrm{~h}$. All the subjects were familiar with the kinds of task to be performed and with the word processing programme.

While performing the tasks, the subjects were interrupted by a telephone call according to a fixed scheme. Telephone calls were chosen because a pilot study (Krediet, 1994) had shown that this was a common source of interruption in reallife work situations. During the telephone call, the subject was told to perform another task, i.e. the interrupting task. Three types of interrupting task were given as follows. (i) A short task differing from the main task. In this case, the subject had to find a piece of information readily available on paper. (ii) A more time-consuming task similar to the main task. The task required a simple correction to be carried out in a document on a disk other than the one being used by the subject. (iii) $A$ comprehensive task differing from the main task. In this case, the subject had to make a text correction on paper. The interrupting tasks were taken from a set of ten tasks, four of which were of type (i); three were of type (ii), and four were of type (iii).

In any session, no, one, or three interrupting tasks were presented. The first session of the day was always the one without interruption; it was considered to be a control condition. The experimental conditions with one and three interruptions were balanced over the other sessions. During sessions with one interruption, either an interrupting task of type (i) or an interrupting task of type (iii) was administered. In the sessions with three interruptions, the order was either (i)(ii)-(iii), or (iii)-(ii)-(i). Thus, the number and the type of interrupting task were counterbalanced. An overview of the experimental conditions in the several groups is given in Table 1 .

\section{Analysis}

To analyse the relationships between the temperament traits and the dependent variables, the scores of similar sessions were averaged. In the calculation of the

Table 1. Type and order of interrupting tasks during experimental sessions for each group

\begin{tabular}{|c|c|c|c|c|c|c|c|}
\hline \multirow[b]{2}{*}{ Group } & \multicolumn{3}{|c|}{ Session on the first day } & \multicolumn{3}{|c|}{ Session on the second day } & \multirow[b]{2}{*}{$n$} \\
\hline & 1 & 2 & 3 & 1 & 2 & 1 & \\
\hline 1 & - & (i) & (i)-(ii)-(iii) & - & (i)-(ii)-(iii) & (i) & 5 \\
\hline 2 & - & (i) & (iii)-(ii)-(i) & - & (iii)-(ii)-(i) & (i) & 5 \\
\hline 3 & - & (i)-(ii)-(iii) & (i) & - & (i) & (i)-(ii)-(iii) & 5 \\
\hline 4 & - & (iii)-(ii)-(i) & (i) & - & (i) & (iii)-(ii)-(i) & 5 \\
\hline 5 & - & (iii) & (i)-(ii)-(iii) & - & (i)-(ii)-(iii) & (iii) & 5 \\
\hline 6 & - & (iii) & (iii)-(ii)-(i) & - & (iii)-(ii)-(i) & (iii) & 4 \\
\hline 7 & - & (i)-(ii)-(iii) & (iii) & - & (iii) & (i)-(ii)-(iii) & 5 \\
\hline 8 & - & (iii)-(ii) (i) & (iii) & - & (iii) & (iii)-(ii)-(i) & 5 \\
\hline
\end{tabular}


averaged resumption time and the averaged interruption time, only the two sessions with three interruptions were involved because in these sessions the categories of interrupting tasks occurred equally frequently. The time spent on the main task was averaged across all six sessions. The numbers of actions within each category in all sessions were summed and divided by the total number of minutes spent on the main tasks. Because of the limitations in the amount of resources available, this was only done in a subsample of 16 subjects. The scores on the measures of the psychological states were also averaged across all sessions.

To test the effects of the interactions between type of interruption and temperamental traits on resumption time, repeated-measures MANOVAs with interaction variables were performed. This method tests whether the effect of a within-subjects factor depends on the level of a between-subjects factor. In this case, the within-subjects factor was the type of interrupting task ((i), (ii), or (iii)). The between-subjects factors were the temperament traits and the action styles. The dependent variable was the resumption time.

\section{RESULTS}

The correlations between the temperament traits and all the variables involved are presented in Table 2. The high correlation between SE and MO indicates that these temperament concepts overlap. This finding is in accordance with the results of some earlier studies (cited by Strelau, 1983, pp. 132-134)). SI did not significantly correlate with the other temperament traits. The correlation between $\mathrm{SE}$ and the number of main actions was not significant, although it was in the expected direction. Clearly, the first hypothesis could not be demonstrated to be correct in this experiment.

$\mathrm{SE}$ correlated negatively with resumption time. This result confirms the second hypothesis that individuals high on SE need less time to resume the main task after an interruption than individuals low on this trait. The relationship between SE and resumption time can be explained by the regulative theory of arousal, according to which a high level of SE affords a protection against the disruptive effects of strong stimuli. The correlation between MO and resumption time was significant. This result confirmed the fifth hypothesis that individuals high on MO are relatively quick in resuming an interrupted task.

The sixth hypothesis, stating that individuals high on MO perform tasks requiring a rapid shift of attention to successive parts of the task more easily and with less effort than subjects low on MO, was tested by relating MO to the time needed for the main tasks and to the effort exerted. As described in the 'Design and procedure' section, the main tasks consisted of many subtasks supposedly requiring high levels of flexibility. Because both correlations were significant in the expected direction, the hypothesis is considered to be confirmed.

SE and MO were positively related to the averaged scores on the PA state scale. MO also correlated negatively to NA state after the sessions. Since significant correlations were also found between the temperament scales and the scores on the PA and NA trait scales, these correlations of temperament with PA state and NA state may have resulted from the general tendency of individuals to experience predominantly positive or negative moods. To exclude this explanation, the 
Table 2. Correlations between temperament traits and other traits and dependent variables: means, standard deviations, and number of subjects

\begin{tabular}{|c|c|c|c|c|c|c|}
\hline Measure and variable & $\begin{array}{l}\text { Strength of } \\
\text { excitation }\end{array}$ & $\begin{array}{l}\text { Strength of } \\
\text { inhibition }\end{array}$ & Mobility & $M$ & SD & $N$ \\
\hline \multicolumn{7}{|l|}{ Pavlov Temperament Scale } \\
\hline Strength of excitation & -- & & & 48.3 & 6.6 & 39 \\
\hline Strength of inhibition & 0.16 & - & & 53.1 & 4.4 & 39 \\
\hline Mobility & $0.67 * * *$ & 0.08 & - & 58.0 & 6.2 & 39 \\
\hline \multicolumn{7}{|c|}{ Action Styles Questionnaire } \\
\hline Goal-directedness & $0.43^{+\dagger}$ & 0.23 & 0.28 & 27.4 & 5.2 & 37 \\
\hline Planfulness & -0.05 & 0.29 & -0.02 & 27.6 & 4.9 & 37 \\
\hline \multicolumn{7}{|l|}{ PANAS } \\
\hline Positive affect (trait) & 0.29 & -0.22 & $0.44^{* *}$ & 35.3 & 3.6 & 38 \\
\hline Negative affect (trait) & $-0.43^{* *}$ & -0.11 & $-0.51 * *$ & 20.8 & 6.7 & 38 \\
\hline Positive affect (state) & $0.45^{\dagger \dagger}$ & 0.03 & $0.43^{\dagger \dagger}$ & 30.5 & 4.6 & 37 \\
\hline Negative affect (state) & -0.28 & 0.07 & $-0.48^{+\dagger}$ & 14.7 & 3.8 & 37 \\
\hline \multicolumn{7}{|l|}{ RSME } \\
\hline Mental effort & -0.15 & 0.00 & $-0.34^{*}$ & 38.2 & 19.3 & 38 \\
\hline \multicolumn{7}{|c|}{ Number of actions observed } \\
\hline Main actions & 0.27 & $0.51^{\dagger}$ & 0.38 & 20.9 & 6.5 & 16 \\
\hline Auxiliary actions & -0.14 & -0.26 & -0.16 & 0.31 & 0.20 & 16 \\
\hline Non-relevant actions & -0.19 & -0.23 & 0.23 & 0.56 & 0.59 & 16 \\
\hline \multicolumn{7}{|l|}{ Performance measures } \\
\hline Resumption time & $-0.40^{\dagger \dagger}$ & -0.08 & $-0.29^{\dagger}$ & 37.8 & 48.1 & 39 \\
\hline Interruption time & 0.04 & -0.11 & 0.04 & 492 & 174 & 39 \\
\hline Time on task & -0.08 & 0.04 & $-0.41^{\dagger \dagger}$ & 2145 & 466 & 39 \\
\hline Errors & -0.23 & 0.22 & -0.11 & 6.9 & 3.3 & 37 \\
\hline
\end{tabular}

Note: PANAS, Positive and Negative Affect Schedule; RSME, Rating Scale Mental Effort. The actions observed are the number of actions per minute; the performance measures are expressed in seconds; the errors are the total number of omitted and wrongly corrected items during the main task.

${ }^{*} p<0.05$, two tailed. ${ }^{* *} p<0.01$, two tailed. ${ }^{* * *} p<0.001$, two tailed. ${ }^{\dagger} p<0.05$, one tailed. ${ }^{+} p<0.01$, one tailed.

corresponding traits of positive and negative moods were partialled out. The partial correlations between MO and the state measures of PA and NA were not significant. Only the partial correlation between SE and PA state with PA trait partialled out was significant: $\operatorname{pr}(34)=0.37, p<0.05$. Therefore, it might be concluded that the fourth hypothesis is partially confirmed.

The seventh hypothesis was confirmed by the rather high correlation between SI and the number of main actions per minute. Because the mean numbers of supportive and non-relevant actions are low, this relationship cannot be explained by alternations between these types of action. This finding suggests that individuals high on SI often interrupt their own actions to undertake new actions belonging to the main task. They do not persevere with an ongoing action for a long time.

Repeated-measures MANOVAs were performed to test the interaction effects between temperament traits and type of interruption on the resumption time. The resulting $F$-values are presented in Table 3. To facilitate the interpretation of the interaction effects the correlations between the temperament traits and the resumption time per type of interruption, the means and the standard deviations of the resumption time per type of interruption are also presented. 
Table 3. Interaction effects between temperament traits and action styles, and type of interruption on resumption time: $F$-values, correlations, and means and standard deviations of resumption time per type of interruption

$r$ with resumption time per type of interruption

\begin{tabular}{llllr} 
Traits & $F$ & (i) & (ii) & \multicolumn{1}{c}{ (iii) } \\
\hline Strength of excitation & $6.42^{* *}$ & -0.12 & $-0.40^{\dagger \dagger}$ & -0.10 \\
Strength of inhibition & 0.65 & 0.09 & -0.12 & 0.20 \\
Mobility & 2.65 & -0.20 & $-0.27^{\dagger}$ & -0.00 \\
Goal-directedness & $4.44^{*}$ & -0.15 & $-0.35^{*}$ & -0.03 \\
Planfulness & 0.09 & -0.07 & -0.05 & 0.21 \\
$\quad M$ resumption time & & 19.9 & 83.1 & 10.5 \\
SD resumption time & & 22.1 & 137.4 & 8.1
\end{tabular}

Note: (i) Short interrupting task different from the main task; (ii) more time-consuming task different from the main task; (iii) comprehensive task different from the main task. The $d f$ value of each $F$ are 2 and 74 . ${ }^{*} p<0.05$, two tailed. ${ }^{* *} p<0.01$, two tailed. ${ }^{\dagger} p<0.05$, one tailed. ${ }^{*} p<0.01$, one tailed.

$\mathrm{SE}$ and goal-directedness interact significantly with type of interruption in their effect on resumption time. The interaction effect with MO was nearly significant $(p=0.06)$. SE correlated most highly with the resumption time after an interrupting task of type (ii). This means that the significant interaction effect was mainly due to differences in the effect of interruptions of type (ii), i.e. interruptions by tasks similar to the main task. Since the correlation was negative and the mean of the resumption time after an interrupting task of type (ii) was highest, individuals low on SE were most disturbed by interrupting tasks similar to the main task. For individuals high on SE, the effect of the type of interrupting task was less strong. These results are in accordance with the third hypothesis in which it was predicted that SE and the similarity between interrupting task and main task would interact in their effect on resumption time.

The significant interaction with goal-directedness was in the same direction. This means that individuals low on goal-directedness need an especially long time to resume the main task after being interrupted by a task similar to the main task.

\section{DISCUSSION}

The present study shows that the regulative theory of temperament is applicable to the types of computer task which are part of the daily work of secretaries and that it can explain some behaviour in the execution of these tasks. It makes clear why some people have more problems resuming the main task after an interruption than others, and why these differences are especially pronounced after an interruption similar to the main task. Individuals low in SE are unable to react adequately in these situations because the interruptions put the stimulative value of the task beyond their optimal level of stimulation. However, in this study, the hypothesis derived from the regulative theory of temperament (Strelau, 1983) that individuals 
low in SE try to minimize the stimulative value by auxiliary actions was not confirmed. This may be due to the fact that the stimulative value of the main tasks was not beyond their optimal level. Moreover, the number of subjects in this part of the study was low, which may have reduced the effect size.

Another important result is the relationship found between the temperament trait of MO and the speed of executing the main tasks. To explain this relationship, we propose to extend the regulative theory of temperament. This is done by distinguishing two aspects of the stimulative value of stimuli. In the regulative theory of temperament it is a characteristic of the stimulus itself with an emphasis on the physical intensity of the stimulus. This fits in with the concept of SE defined as the ability of the individual to react adequately in situations or intense of longlasting stimulation. However, this conception of the stimulative value ignores the often demonstrated fact that a change in the stimulus presented has in itself a stimulative value. According to Day $(1969$, p. 8), 'the sensory systems respond primarily to change in stimulation', because the sensory organs adapt to a constant stimulation. This suggests that the stimulative value of the situation is dependent not only on the intensity of the separate stimuli, but also on the speed of changes between these stimuli. This aspect of the stimulative value corresponds with the concept of MO defined as 'the ability to respond adequately as soon as possible to continuous changes in the environment' (Strelau et al., 1990, p. 213).

In fact, the interruptions in our experiment can be considered switches between tasks. It should be noted that the mean interruption time is rather long: 8 min $11 \mathrm{~s}$. However, most switches occurred between the subtasks of the main task because this task comprised a long series of independent editing instructions. Therefore, it is logical that MO was related to the speed of performing the main tasks. To include this relationship in the regulative theory of temperament, the model presented in Figure 1 has been modified. Figure 2 shows the new hypothetical model.

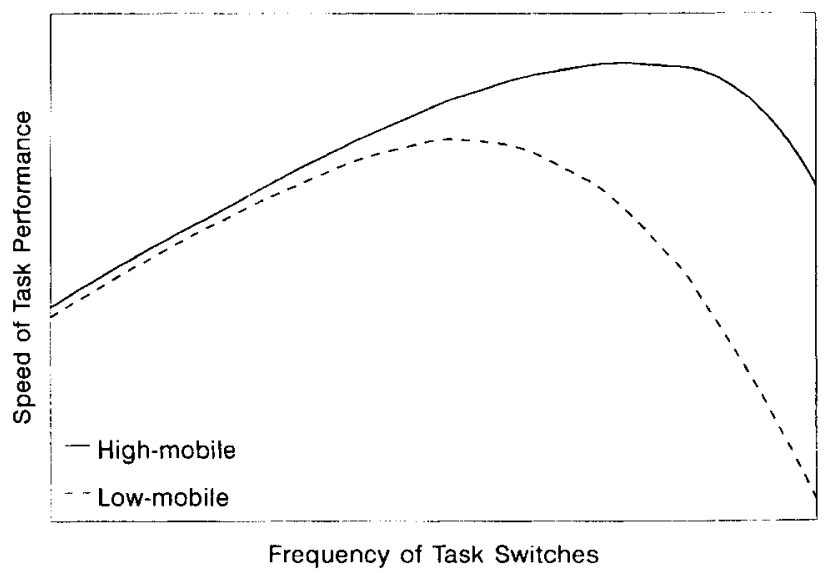

(Monotonous Tasks)

(Hectic Tasks)

Figure 2. Model of the speed of task performance as a function of the frequency of task switches in high-mobile and low-mobile individuals. 
In this model, the stimulative value of the environment is defined by the frequency of switches between tasks or subtasks, and the criterion is the speed of task performance. In monotonous tasks (e.g. video monitoring) the speed of reaction to changes (e.g. something is wrong) is expected to be low because of the low level of arousal, and differences in MO are not supposed to affect the speed of task performance strongly. In tasks with a medium number of switches, the speed of performance is generally high, but individuals high on MO perform more quickly because these changes activate their ability. In hectic tasks, the level of arousal is too high, resulting in disturbances of behaviour (e.g. nervous reactions, inadequate behaviour, or lack of action). In these situations, a high level of MO is supposed to be critical.

Future studies should be directed at this extension of the theory of optimal level of stimulation by investigating several dimensions of the stimulative value of the environment and the personality or temperament traits that match with these dimensions. The stimulative value can be explored by analysing the types of task or situation that increase the level of arousal of subjects finding themselves faced with these tasks or situations. Strelau (1983) described the dimension of the intensity of stimulation. In the present study, the frequency of switches between tasks was emphasized. Other dimensions of the stimulative value of the environment are the novelty of stimuli, and the physical and social risk people run (see Zuckerman, 1979). Undoubtedly, some people have a higher optimal level than others on each of these dimensions. The next step is to investigate the corresponding individual differences discriminating these people and to study how these individual differences relate to criteria on several levels of the stimulative value of the environment. Several behavioural measures should be used as criteria, and in order to study the physiological basis of the theory, the level of arousal should also be measured.

The strengths of the present study are the high ecological validity of the experiment, the sophisticated research design to control for many confounding effects, the test of theoretical or empirical based hypotheses, and the use of psychometrically sound measures. However, a limitation of this study is the fact that a relatively small number of subjects was involved.

The results of this study may also be of relevance for practitioners. To the degree that our findings will be confirmed in subsequent research, we would suggest the following implications. First, in personnel selection, the temperament traits of SE and MO may be used as predictors of task performance in relevant jobs. Applicants low on SE can be expected to have some problems in resuming their task when interrupted. With a high number of interruptions, these applicants will not get on with their task. Besides, they will experience less positive affect during task performance than applicants high on SE. It is predicted that applicants low on MO will be slow in task performance and need more effort to do the same job. They are also slow to resume a task after interruption.

Second, some suggestions for job redesign and placement can be derived from this study. Employees low on SE and MO cannot perform well when they are often interrupted during their work. Therefore, they have to be placed in positions with relatively few interruptions. In the case of two or more secretaries working together, the work may be divided in such a way that it is more in congruence with their temperaments. 


\section{REFERENCES}

Cellier, J. M. and Eyrolle, H. (1992). 'Interference between switched tasks', Ergonomics, 35: 25-36.

Day, R. H. (1969). Human Perception, Wiley, Sidney.

Eysenck, H. J. (1967). The Biological Basis of Personality, Thomas, Springfield, IL.

Field, G. E. (1987). 'Experimentus interruptus', SIGCHI Bulletin, 19: 42-46.

Fiske, D. W. and Maddi, S. R. (Eds) (1961). Functions of Varied Experience, Dorsey, Homewood, IL.

Frese, M., Stewart, J. and Hannover, B. (1987). 'Goal orientation and planfulness: action styles as personality concepts', Journal of Personality and Social Psychology, 52: 1182-1194.

Furnham, A. and Zacherl, M. (1986). 'Personality and job satisfaction', Personality and Individual Differences, 7: 453-459.

Gillie, T. and Broadbent, D. (1989). 'What makes interruptions disruptive? A study of length, similarity, and complexity', Psychological Research, 50: 243-250.

Guilford, J. P. (1967). The Nature of Human Intelligence, McGraw-Hill, New York.

Hebb, D. O. (1955). 'Drives and the C.N.S. (central nervous system)', Psychological Review, 62: 243-254.

Johansson, G. and Aronsson, G. (1984). 'Stress reactions in computerized administrative work', Journal of Occupational Behavior, 5: 159-181.

Kahneman, R. L. (1973). Attention and Effort, Prentice Hall, Englewood Cliffs, NJ.

Klimov, E. A. (1959). 'Individual occupational features of female textile multi-machine operators with respect to the mobility of nervous processes', Voprosy Psikhologii, 5: 66-76 (in Russian).

Kopytova, M. R. (1964). 'Individual style of professional activity of operators determined by strength of the nervous system as regards excitation', Voprosy Psikhologii, 10: 24-33 (in Russian).

Koscielak, R. (1979). 'The role of nervous system traits in inventive creativity', Polish Psychological Bulletin, 10: 225-232.

Krediet, I. (1994). Types of Interruptions and their Effects on Mental Information Work, WORC Paper No. 94.07.039/4, Tilburg University, Tilburg.

Mündelein, H. and Schönpflug, W. (1983). 'Regulation und Fehlregulation im Verhalten. VIII: über primäre (unmittelbar zielgerichtete) und sekundäre (auxiliäre und präventive) Anteile von Tätigkeiten' ['Behavioral regulation and disregulation. VIII: on primary (goaloriented) and secondary (auxiliary and preventive) components of activity'], Psychologische Beiträge, 25: 71-84.

Nebylitsyn, V. D. (1972). Fundamental Properties of the Human Nervous System, Plenum, New York.

Pavlov, I. P. (1955). Selected Works, Foreign Languages Publishing House, Moscow.

Roe, R. A., Van den Berg, P. T., Zijlstra, F. R. H., Schalk, M. J. D., Taillieu, T. C. B. and Van der Wielen, J. M. M. (1993). 'New concepts for a new age: information service organizations and mental information work', The European Work and Organizational Psychologist, 3:163-176.

Strelau, J. (1977). 'Behavioral mobility versus flexibility and fluency of thinking: an empirical test of the relationship between temperament and abilities', Polish Psychological Bulletin, 8 : $75-82$.

Strelau, J. (1983). Temperament-Personality-Activity, Academic, London.

Strelau, J., Angleitner, A., Bantelmann, J. and Ruch, W. (1990). 'The Strelau Temperament Inventory-Revised (STI-R): theoretical considerations and scale development', European Journal of Personality, 4: 209-235.

Strelau, J. and Zawadzki, B. (1993). 'The Formal Characteristics of 'Behaviour-Temperament Inventory (FCB-TI): theoretical assumptions and scale construction', European Journal of Personality, 7: 313-336.

Thomas, A. and Chess, S. (1977). Temperament and Development, Brunner-Mazel Publishers, New York.

Van Heck, G. L., De Raad, B. and Vingerhoets, A. J. J. M. (1993). 'De Pavlov-TemperamentSchaal (PTS)' ['The Pavlov Temperament Scale (PTS)'] Nederlands Tijdschrift voor de Psychologie, 48: 141-142. 
Watson, D., Clark, L. A. and Tellegen A. (1988). 'Development and validation of brief measures of positive and negative affect: the PANAS scales', Journal of Personality and Social Psychology, 54: 1063-1070.

Zeigarnik, B. (1927). 'Das Behalten erledigter und unerledigter Handlungen' ['Retaining completed and not-completed actions'], Psychologische Forschung, 9: 1-85.

Zijlstra, F. R. H. (1991). Efficiency in Work Behavior: A Design Approach for Modern Tools, Doctoral dissertation, Delft University of Technology, Delft.

Zuckerman, M. (1979). Sensation Seeking: Beyond the Optimal Level of Arousal, Erlbaum, Hillsdale, NJ. 